\title{
Inheritance and Innovation of Traditional Excellent Chinese Culture in the New Era
}

\author{
Zhang Jing ${ }^{a}$, Yan Fengchi ${ }^{b}$ \\ Zaozhuang Vocational College of Science \& Technology, Tengzhou, 277599, Shan Dong, China \\ azgxzhangjing@163.com, b13869452649@126.com
}

Keywords: new era; traditional excellent Chinese culture; inheritance and innovation

\begin{abstract}
In the new era, the outstanding traditional Chinese culture needs further inheritance and innovation. The traditional excellent Chinese traditional culture is the spiritual lifeline of the Chinese nation and the outstanding advantage of the Chinese nation. It is an important source of cultural self-confidence. Chinese ideology and culture embody, outlook on world, life, values and aesthetic standards that the Chinese nation has formed and inherited from generation to generation in production and life. There is an urgent need to dig into the value of traditional excellent Chinese culture, to further stimulate the vitality of excellent traditional Chinese culture, and to implement in depth the spirit of General Secretary Xi Jinping's series of important speeches and new ideas and new strategies of governing the country and politics. Closely surrounding Chinese Dream aimed to realize the great rejuvenation of the Chinese nation, it is necessary to thoroughly implement the new development concept, adhere to the people-centered work orientation, and continue to take the socialist core values as the guide. Inheritance of Chinese culture genes will constantly enhance the vitality and influence of traditional excellent Chinese culture, create new brilliant Chinese culture.
\end{abstract}

\section{Introduction}

Culture is the blood of the nation and the spiritual homeland of the people. Cultural self-confidence is a more basic, deeper, and more lasting force. The unique concept, wisdom, magnanimity, charm of Chinese culture, build a socialist cultural power, strengthen the soft power of the national culture, and realize the great restoration of the excellent Chinese traditional culture by the Chinese nation, Chinese Dream. In the context of the new era, we need to inherit and innovate. In his important speech on 1 July, General Secretary Xi Jinping pointed out that cultural self-confidence is more fundamental, broader and deeper ${ }^{[1]}$. The sixth Plenary session of the 18 CPC Central Committee stressed that: we must firmly believe in the road, theory, system and culture of socialism with Chinese characteristics, the ideals and struggles of the Chinese people, the values and spiritual world of the Chinese people, and the self-confidence of the Chinese people, always rooted in the fertile soil of Chinese excellent traditional culture. With the progress of history and constantly new, with the times, Chinese excellent traditional culture is the spiritual lifeline of the Chinese nation, it is the outstanding advantage of the Chinese nation, it is an important source of our cultural self-confidence. Strengthening cultural self-confidence requires us to thoroughly study and implement General Secretary Xi Jinping's series of important expositions on inheriting and carrying forward the excellent traditional Chinese culture, to cherish the value, to use the past for the present, and to carry forward the essence for innovation and development.

\section{Great significance of inheriting and carrying forward the excellent traditional Chinese culture}

The Chinese culture has a long history and brilliant brilliance. The excellent Chinese traditional culture, conceived in the course of more than 5000 years of civilization development, it accumulates the deepest spiritual pursuit of the Chinese nation, represents the unique spiritual symbol of the Chinese nation, and it is the constant growth of the Chinese nation. The rich nourishment of 
development and growth is the cultural fertile soil of socialism with Chinese characteristics, it makes the prominent advantage of contemporary China's development, and it makes contribution to the continuation and development of Chinese civilization and the promotion of the progress of human civilization. We should fully understand the significance of inheriting and carrying forward the outstanding Chinese traditional culture ${ }^{[2]}$.

In leading the people in carrying out revolution, construction, and reform, the Communist Party of China consciously shouldered the historical responsibility of inheriting and developing China's outstanding traditional culture, and was a faithful successor to China's outstanding traditional culture. Since the 18 National Congress of the Party, under the leadership of the CPC Central Committee with Comrade Xi Jinping as the core, party committees and governments at all levels have become more conscious and more proactive in promoting the inheritance and development of China's outstanding traditional culture. A series of innovative and fruitful work has been carried out, which has strengthened the cohesion, influence and creativity of China's outstanding traditional culture. At the same time, we should see that with the profound changes in our country's economy and society, the opening up to the outside world has been expanding day by day. With the rapid development of Internet technology and new media, the exchange of various ideas and cultures is becoming more frequent. Therefore, it is urgent to deepen the understanding of the importance of Chinese excellent traditional culture and to further strengthen cultural self-consciousness and cultural self-confidence. It is urgent to dig deep into the value connotation of Chinese excellent traditional culture, to further stimulate the vitality and vitality of Chinese excellent traditional culture, and to strengthen policy support. It is an important strategic task for building a socialist cultural power to build a development system for the inheritance and development of Chinese excellent traditional culture. It is an important strategic task to carry on the Chinese context and comprehensively enhance the cultural literacy of the people. It has great significance to safeguard the national cultural security, strengthen the soft power of national culture, and promote the modernization of national governance system and governance ability ${ }^{[3]}$.

\section{Strengthening cultural confidence is the foothold of inheriting and innovating Chinese excellent traditional culture}

To strengthen cultural self-confidence, we need to fully understand the great significance of inheriting and carrying forward the outstanding Chinese traditional culture. Our nation has a history of thousands of years, it has its own characteristics, and has many precious goods. Today's China is a development of historical China, we are Marxist historicists, and we should not cut off history. From Confucius to SUN Zhongshan, we should sum up, carry on this precious legacy. "Comrade Deng Xiaoping once pointed out: " We should use history to educate young people and educate the people. "understanding Chinese history is a spiritual motive force for China's development." said Comrade Jiang Zemin and Comrade Hu Jintao ${ }^{[4]}$.

Since the 18 National Congress of the Party, General Secretary Xi Jinping has repeatedly stressed that Chinese Communists are not historical nihilists, not cultural nihilists, but inheritors and promoters of China's outstanding traditional culture. Human beings have had a history of civilization for thousands of years. Any country, a nation, has come to this day in the process of carrying on the past and opening up to the future. Contemporary China is the continuation and development of historical China. Contemporary Chinese ideology and culture are also the inheritance and sublimation of Chinese traditional ideology and culture. In order to understand today's China and today's Chinese people, it is necessary to have a thorough understanding of China's cultural lineage. Accurately grasp the cultural soil that nourishes the Chinese people. Chinese ideology and culture embody the world outlook, outlook on life, values, aesthetics and so on that the Chinese nation has formed and inherited in production and life from generation to generation. Among them, the core content has become the most basic cultural genes of the Chinese nation. These most basic cultural genes have been integrated into the blood of the Chinese sons and daughters from generation to generation. They are manifested in their demeanor and manner. It is the Chinese people who are honoring their duties, knowing that they are constantly changing, and 
doing business. The unique symbol that gradually formed in the course of establishing meritorious service and establishment is different from other nationalities. The profound traditional Chinese culture accumulates the most profound spiritual pursuit of the Chinese nation, and it is the rich nourishment of the Chinese nation's growth and growth. It is also a prominent advantage of the Chinese nation and our most profound cultural soft power. Only by persisting in moving from history to the future and developing and advancing from continuing the national cultural lineage, can we do a good job in today's cause. It is necessary to draw nutrition and wisdom from the excellent traditional culture formed and accumulated by the Chinese nation from generation to generation, to continue the cultural gene, to extract the essence of thought, to show the spiritual charm, and to activate the vitality of Chinese excellent traditional culture with the spirit of the times [5].

Marx said: "People create their own history, but they do not create whatever they want, not in the conditions they choose, but directly meet, set, create from the conditions inherited from the past. " the excellent Chinese traditional culture is undoubtedly the established historical and realistic conditions of the Chinese people. Lenin said: "Only by understanding all the wealth created by mankind can we enrich our minds, so as to become Communists. " therefore, the excellent Chinese traditional culture is the indispensable foundation and starting point for us to build a socialist advanced culture, this is the profound understanding of the excellent Chinese traditional culture, it is an important aspect representing the fundamental interests of the overwhelming majority of the Chinese people, it is a cultural strategic policy supported by the masses of the people, and it is an important component of socialism with Chinese characteristics.

\section{Intrinsic value of the inheritance and innovation of Chinese excellent traditional culture}

The excellent Chinese traditional culture contains rich moral concepts and norms, such as the rise and fall of the world, equal responsibility for the responsibility of the sense of responsibility, loyalty to serve the country, rejuvenate the patriotic feelings of China, worshiping morality to the good, the social customs of the wise, filial piety and loyalty, The concept of honor and disgrace of courtesy and integrity reflects the value standard of judging right and wrong, and influences the behavior of Chinese people imperceptibly. In order to inherit and develop Chinese excellent traditional culture, we must vigorously carry forward self-improvement, work hard for the masses of people, and help the people in distress. Act bravely, filial piety and love relatives and other traditional Chinese virtues.

To strengthen cultural self-confidence, we must scientifically evaluate the intrinsic value of China's outstanding traditional culture. Inherit and innovate Chinese excellent traditional culture. General Secretary Xi Jinping takes a historical materialism perspective. Standing at the height of realizing the great rejuvenation of the Chinese nation, the excellent Chinese traditional culture is regarded as the "root" and "soul" of the Chinese nation.

Excellent Chinese traditional culture is the "root" and "soul" of the Chinese nation. General Secretary Xi Jinping pointed out: civilization, especially ideological culture, is the soul of a country and a nation. No matter which country or nation it is, if you do not cherish your own ideology and culture and lose the soul of thought and culture, this country, this nation, cannot stand up. For the Chinese nation, our excellent traditional culture is the "root" and "soul" of our Chinese nation. The reason why Chinese civilization has survived for more than 5,000 years is the only civilization that has not been interrupted among the world's major ancient civilizations, because it has not abandoned tradition. Without cutting off the spiritual lifeline, its "root" its "soul" has been extended to this day. After thousands of years of vicissitudes of life, the 56 nationalities and more than 1.3 billion people in our country have been tightly condensed together, which is a remarkable struggle we have experienced together. Is a beautiful home that we create together, is the national spirit that we cultivate together, and runs through it, the most important thing is the ideal and belief we hold together. The outstanding Chinese traditional culture emphasizes the status and responsibility of the human being in the society. It is the most fundamental spiritual gene of the Chinese nation to pay attention to the ideals, beliefs and moral pursuits of self-improvement, moral integrity and good will. 
The excellent traditional Chinese culture advocates benevolence, respect for the people, honesty, justice and harmony. The idea of seeking common ground has been firmly accumulated in the mode of thinking and behavior of the Chinese people, and has profoundly influenced generations of Chinese sons and daughters. The excellent traditional Chinese culture is a spiritual home shared by Chinese people at home and abroad, and it is the vitality of the Chinese nation. Cohesion is an important source of creativity. Therefore, we must cherish the root and soul.

\section{Vigorously carry forward the excellent Chinese traditional culture}

In the context of the new era, to strengthen cultural self-confidence, we must vigorously carry forward the excellent Chinese tradition. There are two wrong ways to treat traditional culture: one is cultural nihilism, in which traditional culture is said to be dark. Thinking that Chinese traditional culture is feudal culture, serves the feudal ruling class, it is a historical burden, and is an inert force that drags the advance of the times. It is the dross that should be completely abandoned. One is cultural conservatism, which clung to the old cultural traditions. At the end of the 20th century, the Soviet Union broke up, Eastern Europe changed dramatically, and the international communist movement fell into a low ebb. At that time, there began to be a theory of reviving Confucianism in China, and then it gradually developed. Especially in recent years, some people try to replace Marxism with Confucianism, or turn Marxism into Confucianism. General Secretary Xi Jinping insisted on the principle of taking the essence of traditional culture, dismissing the dross, criticizing and transforming the past, bringing forth the old and bringing forth the new, and stressing that "we must properly handle the relationship between inheritance and creative development." Emphasis should be placed on creative transformation and innovative development. "it is necessary to treat cultural traditions scientifically, propose that only by not forgetting history can we open up the future, and be good at inheriting and innovating. We should be good at organically unifying the promotion of outstanding traditional culture with the development of real culture. Combining closely, developing in succession, inheriting in developing, we insist on using the past for the present when studying, study and apply traditional culture, bring forth the new from the past. Combining with the new practice and the requirements of the times to make a correct choice between the past and the present. We should persist in using the past for the present, learn from the past and learn from the present, persist in the treatment of the past and the present, it has the inheritance of sublation and abandonment, and we should not make great efforts to realize the creative transformation of the traditional culture by making use of the past and the present, and using the past as the wrong and the present, and try to realize the creative transformation of the traditional culture. Innovative development, we make it compatible with real culture and serving the tasks of the times with cultural people. Therefore, it is necessary to strengthen the excavation and elucidation of Chinese excellent traditional culture, to transcend time and space, transcend the country, and be full of eternal charm. The cultural spirit with contemporary value is carried forward, and the achievements of contemporary Chinese culture innovation, which inherits the excellent traditional culture and carries forward the spirit of the times based on our country so that facing the world and spreading out.

\section{Conclusions}

Chinese excellent traditional culture is the moral source of cultivating the core values of socialism. Chinese traditional culture is famous for its characteristic of moral education. Our nation needs to further strengthen its cultural self-consciousness and cultural self-confidence. There is an urgent need to dig into the value connotation of Chinese excellent traditional culture, to further stimulate the vitality and vitality of Chinese excellent traditional culture, and to implement in depth the spirit of General Secretary Xi Jinping's series of important speeches and new ideas and new strategies of governing the country and politics. Chinese Dream, who closely revolves around the realization of the great rejuvenation of the Chinese nation, deeply implements the new development concept, adheres to the people-centered work orientation, and adheres to the socialist core values as 
the guide in the new era. In order to inherit and innovate the excellent Chinese traditional culture, we need to apply the wisdom discovered and developed by mankind today, inherit and carry forward it in the light of the conditions of the times, endow it with new meanings, and make it benefit mankind. It has not only had a profound impact on the development of China, but also made a great contribution to the progress of human civilization. Be good at organically unifying the promotion of excellent traditional culture and the development of realistic culture, closely combining it, developing in succession and inheriting in developing. It is necessary to persist in the study, study and application of traditional culture make the past serve the present and bring forth new from the past. We must adhere to the Chinese cultural position. Inheritance of Chinese culture genes, constantly enhance the vitality and influence of Chinese excellent traditional culture, create new brilliant Chinese culture.

\section{References}

[1] Arefi M M, Zarei J, Karimi H R. Adaptive output feedback neural network control of uncertain non-affine systems with unknown control direction[J]. J of the Franklin Institute, 2014, 351(8): 4302-4316.

[2] Mahmoud E E. Complex complete synchronization of two nonidentical hyperchaotic complex nonlinear systems[J]. Mathematical Methods in the Applied Sciences, 2014, 37(3): 321-328.

[3] Palomares I, Martinez L, Herrera F. A consensus model to detect and manage non-cooperative behaviors in large scale group decision making[J]. IEEE Trans on Fuzzy System, 2014, 22(3): 516-530.

[4] CHEN S, WANG G, JIA W. Cluster-group based trusted computing for mobile social networks using implicit social behavioral graph [J]. Future Generation Computer Systems, 2016,55: 391-400.

[5] Xu Mingdi, Gao Yang, Gao Xueyuan, Zhang Fan. Correspondence property-based platform configuration attestation. Journal of Computer Applications, 2018, 38(2): 337-342. 